\title{
O uso de libras com alunos surdos nas disciplinas de Matemática e Ciências
}

\author{
The use of pounds with deaf students in the Math and Science disciplines \\ El uso de libras con estudiantes sordos en las disciplinas de Matemáticas y Ciencias
}

Recebido: 09/04/2021 | Revisado: 16/04/2021 | Aceito: 12/05/2021 | Publicado: 28/05/2021

\author{
Michelle Gonçalves Beserra de França \\ ORCID: https://orcid.org/0000-0003-1673-8846 \\ Instituto Federal de Educação, Ciência e Tecnologia do Ceará, Brasil \\ E-mail: mibeserrafranca2013@gmail.com \\ Maria Cleide da Silva Barroso \\ ORCID: https://orcid.org/0000-0001-5577-9523 \\ Instituto Federal de Educação, Ciência e Tecnologia do Ceará, Brasil \\ E-mail: ccleideifcemaraca@gmail.com
}

\begin{abstract}
Resumo
O presente artigo tem como objetivo geral fazer uma investigação a respeito da origem da língua brasileira de sinais (LIBRAS), como também, uma fundamentação teórica em análises de produções textuais de contribuintes do ensino de LIBRAS. E tem como demais objetivos: refletir a respeito do ensino de matemática e ciências para alunos surdos, onde é abordado o ensino das disciplinas mostrando as percepções docentes relacionadas ao seu fazer pedagógico; discutir a maneira de proceder do professor quando se depara em uma sala de aula com alunos surdos, como também visa a importância de compreender o uso da LIBRAS para se chegar ao raciocínio lógico do aluno e com o estímulo de diversas metodologias. A pesquisa expõe a necessidade da prática educativa e no formato de como o professor poderá adotar novos mecanismos de ensino, com o objetivo de promover significativamente a melhoria da estrutura linguística e cognitiva que favorecerá o processo de ensino-aprendizagem dos surdos.
\end{abstract}

Palavras-chave: Percepções docentes; Libras; Raciocínio lógico; Metodologias diversas; Ensino.

\begin{abstract}
The present article has as general objective to make an investigation about the origin of the Brazilian sign language (LIBRAS), as well as, a theoretical foundation in analysis of textual productions of contributors of the teaching of LIBRAS. And it has as other objectives: to reflect on the teaching of mathematics and science for deaf students, where the teaching of the subjects is approached showing the teachers' perceptions related to their pedagogical practice; discuss the teacher's way of proceeding when faced with deaf students in a classroom, as well as the importance of understanding the use of LIBRAS to arrive at the student's logical reasoning and with the encouragement of different methodologies. The research exposes the need for educational practice and in the format of how the teacher can adopt new teaching mechanisms, with the aim of significantly promoting the improvement of the linguistic and cognitive structure that will favor the teaching-learning process of the deaf.
\end{abstract}

Keywords: Teaching perceptions; Pounds; Logical reasoning; Various methodologies; Teaching.

\section{Resumen}

El presente artículo tiene como objetivo general realizar una investigación sobre el origen de la lengua de signos brasileña (LIBRAS), así como, una base teórica en el análisis de las producciones textuales de los colaboradores de la enseñanza de LIBRAS. Y tiene como otros objetivos: reflexionar sobre la enseñanza de las matemáticas y las ciencias para estudiantes sordos, donde se aborda la enseñanza de asignaturas mostrando las percepciones docentes relacionadas con su práctica pedagógica; discutir la forma de proceder del docente ante los alumnos sordos en el aula, así como la importancia de comprender el uso de LIBRAS para llegar al razonamiento lógico del alumno y con el estímulo de diversas metodologías. La investigación expone la necesidad de la práctica educativa y en el formato de cómo el docente puede adoptar nuevos mecanismos de enseñanza, con el objetivo de promover significativamente la mejora de la estructura lingüística y cognitiva que favorecerá el proceso de enseñanza-aprendizaje de los sordos.

Palabras clave: Enseñar percepciones; Libras; Raciocinio lógico; Varias metodologías; Enseñanza.

\section{Introdução}

Com o reconhecimento da Língua Brasileira de Sinais - LIBRAS, como língua oficial dos surdos pela Lei Federal $\mathrm{n}^{\circ}$ 10.436, de 24 de abril de 2002 (BRASIL, 2002), e com a regulamentação por meio do Decreto $\mathrm{n}^{\circ} 5.626$ de 22 de dezembro de 2005 (BRASIL, 2005), ocorreram mudanças significativas em relação às comunidades surdas. Diz o Art. $1^{\circ}$ da Lei Federal: 
É reconhecida como meio legal de comunicação e expressão a Língua Brasileira de Sinais - Libras e outros recursos de expressão a ela associados.

Parágrafo único. Entende-se como Língua Brasileira de Sinais - Libras a forma de comunicação e expressão, em que o sistema linguístico de natureza visualmotora, com estrutura gramatical própria, constituem um sistema linguístico de transmissão de ideias e fatos, oriundos de comunidades de pessoas surdas do Brasil.

O termo educação inclusiva iniciou-se nos Estados Unidos, através de uma Lei Pública no 94.142 de 1975. Há arquivos históricos datados desde o século XV que tratam de crianças deformadas jogadas nos esgotos da Roma Antiga, como também era permitido aos pais ceifar a vida das crianças com deformidades físicas, pela prática do afogamento. Na Grécia, pessoas nascidas "disformes" iam para a eliminação, que se tratava de uma exposição, ou abandono ou, ainda, atiradas do aprisco de uma cadeia de montanhas chamada Taygetos. Essas pessoas poderiam ser imoladas e isso não constituia nada contra a ética e a moral da época. As explicações dadas para a deficiência assumiam um cunho místico ou sobrenatural. O início da Idade Média, foi marcado por precárias condições de vida e de saúde das pessoas. A população ignorante encarava o nascimento de pessoas com deficiência como castigo de Deus. Os supersticiosos viam nelas poderes especiais de feiticeiros ou bruxos. As crianças que sobreviviam eram separadas de suas famílias e quase sempre ridicularizadas. Em 1620, na Espanha, Juan Pablo Bonet (15791633), padre espanhol, educador e pioneiro na educação de surdos, escreveu sobre as causas das deficiências auditivas e dos problemas da comunicação, condenando os métodos brutais e de gritos para ensinar alunos surdos.

A partir de 1855 obteve-se um padrão inicial da educação dos surdos no Brasil. No caso, a LIBRAS deriva da Língua de Sinais Franceses (LSF), trazida pelo professor surdo Hernest Huet (1858-1917) médico neurologista francês, convidado por Dom Pedro II e participante da fundação da primeira escola para surdos na cidade do Rio de Janeiro, em 26 de setembro de 1857, que ficou conhecida como Imperial de Surdo Mudo, visto atualmente como INES - Instituto Nacional de Educação de Surdos (Goldfeld, 2002). Hernest Huet apresentou grandes dificuldades para instituir o INES, pois os brasileiros não o reconheciam como cidadão e o seu trabalho pedagógico não era apreciado (Strobel, 2008).

A Declaração de Salamanca é considerada um dos principais documentos mundiais que visam à inclusão social e o Brasil é signatário dessa orientação. Esta declaração oportuniza a inserção da educação especial no panorama de educação para todos, firmado na decada de 90 (Brasil, 1994).

Segundo o documento, a escola inclusiva é onde todas as crianças deveriam aprender juntas, independentemente de quaisquer dificuldades ou diferenças que possam existir. Admite-se que a prática da educação inclusiva é a forma capaz de combater a discriminação e permitir uma participação plena e efetiva na sociedade em igualdades de condições com outras pessoas.

O aluno com deficiência não era objeto de estudo da Pedagogia, nem foi admitido no sistema regular num passe de mágica. Até meados do século XX, o pouco diferenciava entre os números, graus, níveis e modalidades de comprometimento mental. A criança não era impedida, sempre, de frequentar a escola; mas eram trabalhados, daí a desnecessidade de sua escolarização e a ênfase em terapias individuais, como fonoaudiologia, psicologia, fisioterapia, entre outras (Pereira \& Santos, 2009, p.266).

Já a Constituição de 1988 (Brasil, 1988), conhecida como a constituição cidadã, estabelece no seu texto a obrigação dos entes da sociedade para com a educação, em seu art. 205, evoca: "A educação, direito de todos e dever do Estado e da família, será promovida e incentivada com a colaboração da sociedade, visando ao pleno desenvolvimento da pessoa, seu preparo para o exercício da cidadania e sua qualificação para o trabalho."

O Estatuto da Criança e do Adolescente, lei n 8.069, de 13 de julho de 1990 e a Lei de Diretrizes e Bases da educação nacional n ${ }^{\circ}$ 9394/96, estabelecem o atendimento especializado aos portadores de deficiência.

Dessa forma, portanto, as propostas que objetivavam a inclusão dos surdos no ensino regular passaram a ser reformuladas a partir de uma nova perspectiva, onde as instituições deveriam reconhecer, respeitar e considerar as categorizações 
dos surdos na elaboração de suas propostas pedagógicas, ocorrendo somente na década de 1990 (Guarinello, 2006).

Ademais, considera-se como divisor de águas para a comunidade surda o tema da redação do Enem em 2017, que abordou os desafios para a formação educacional de surdos no Brasil. Com essa proposta deu-se início uma discussão nacional através da mídia e com isso, a educação de surdos teve maior visibilidade.

Há algumas décadas a educação no Brasil passa por inúmeras discussões, debates e reformas, buscando mudanças que possibilitem um ensino autêntico e competente. Entretanto, Nóvoa (2009), destaca: "a educação vive um tempo de grandes incertezas e de muitas perplexidades. Sentimos a necessidade da mudança, mas nem sempre conseguimos definir-lhe o rumo. Há um excesso de discursos, redundantes e repetitivos, que se traduz numa pobreza de práticas."

A escolha do referido tema ocorreu devido à busca por informações sobre a utilização da LIBRAS nas aulas de Matemática e Ciências no decorrer dos anos posteriores a pós-graduação.

As indagações do professor quando tem um aluno com necessidades especiais são as seguintes: será possível estabelecer alguma comunicação com este aluno sem conhecer os sinais específicos? Será que estas crianças aprendem da mesma maneira dos alunos ouvintes? Poderei aplicar uma aula sem um intérprete na sala de aula? E ainda, independente da disciplina, relacionarse com uma metodologia a ser utilizada, tendo conhecimento que nem todas as escolas possuem um profissional específico.

É preciso considerar, antes de tudo, que o professor deve buscar condições que favoreçam e aperfeiçoe seus conhecimentos por meio de diversas formas adequadas, dentre elas: cursos, palestras, conversas, situações que possibilitarão o engrandecimento do seu trabalho, não se limitando, apenas, aos conhecimentos adquiridos durante seu período de formação. Ramalho \& Núñez (2011, p. 73), reiteram que este aspecto de formação:

[...] é mais que instrução ou aprendizagem de conhecimentos e formação de habilidades e de competências, pois inclui, entre outras coisas, interesses, necessidades, intenções, motivações, caráter, capacidades, condutas, crenças, atitudes e valores. [...] é o tipo de atividade que o professor se apropria da cultura profissional e modifica [...] elementos chaves do seu agir profissional, de forma a influenciar no desenvolvimento profissional.

A problemática apresentada permeia a falta de entendimento por parte de alguns professores, núcleo gestor e pais, sobre a importância da LIBRAS na aprendizagem do aluno com deficiência auditiva, de forma que a responsabilidade da apresentação do conteúdo das disciplinas não fique única e exclusivamente na responsabilidade dos intérpretes de LIBRAS. É notória que não existe, principalmente na escola pública, uma atenção em capacitar os professores para o desenvolvimento de atividades com uso da linguagem de sinais.

Segundo Alves e Ramos (2018): “[...]Os cursos de formação de professores devem promover a possibilidade de capacitação destes profissionais, para que trabalhem a favor da construção de sociedades mais democráticas, de uma escola inclusiva e emancipatórias." É imprescindível, que na formação, o professor tenha conhecimento, para que posteriormente, ao receber um aluno com deficiência não tenha dificuldade de repassar seu conteúdo e que o mesmo tenha uma compreensão na elaboração de suas metodologias.

A responsabilidade de garantir a seguridade de uma educação de qualidade para as pessoas com deficiências, resguardando-as de toda forma de violência, negligência e discriminação, não é somente dever do Estado e da família, mas também de toda sociedade.

No momento, a língua de sinais, precisa deixar de ser somente uma garantia na legislação, mas sim, uma promoção do conhecimento gerado a partir de discussões e gerar métodos e didáticas para permitir aos profissionais da educação a realização de um ensino de qualidade igualitária para todos os alunos.

É essencial um estudo mais complexo, principalmente, enquanto não houver um direcionamento à proposta de formação do professor para melhor desempenhar esta função e lidar com essas situações. A falta de conhecimento, que seja o básico, prejudica tanto o aprendizado do aluno como o desenvolvimento do professor. 
Desse modo, este trabalho tem como principal objetivo compreender a importância do uso da LIBRAS para a melhoria no processo ensino-aprendizagem nas disciplinas de matemática e ciências, tendo como estudo de caso crianças surdas em uma sala regular do fundamental I, sejam escolas particulares ou públicas.

\section{Concepções sobre o uso da LIBRAS com alunos surdos nas disciplinas de Matemática e Ciências}

Para a realização desta pesquisa qualitativa foi efetuado um levantamento bibliográfico de caráter revisional e metodológico, com o intuito de investigar a importância da LIBRAS nos resultados do processo de ensino e aprendizagem de crianças surdas nas áreas de exatas e ciências no fundamental I.

A pesquisa bibliográfica é aquela que se realiza a partir do registro disponível, decorrente de pesquisas anteriores, em documentos impressos, como livros, artigos, teses etc. Utiliza-se de dados ou de categorias teóricas já trabalhados por outros pesquisadores e devidamente registrados. Os textos tornam-se fontes dos temas a serem pesquisados. O pesquisador trabalha a partir das contribuições dos autores dos estudos analíticos constantes dos textos. (Severino,2013,p.105)

Tendo em vista a importância de uma nova aplicabilidade das aulas como ferramenta de reter a atenção dos alunos, foi observado que esta temática deve ser discutida por vários especialistas da área da educação, bem como entre os próprios professores, seja de escolas públicas ou particulares.

Cabe salientar, ainda, que essa pesquisa foi fundamentada nos escritos de teóricos como: Schön (1992), Cukierkorn (1996), Williams (2000), Nogueira \& Machado (1996), Pimenta (2001), Silva (2018) entre outros.

O uso de sinais é uma nova aplicabilidade dos mais diversos conteúdos em sala de aula. Considera-se como uma alternativa, por inúmeros educadores, que sentem nos alunos a importância de uma nova necessidade na prática educativa e na forma como o professor poderia adotar diferentes mecanismos, com o objetivo de melhorar o processo de ensino-aprendizagem.

Para muitos, pode parecer um procedimento correto, mas as perguntas são: o aluno, nosso principal interessado, está assimilando tal conteúdo? Se há novos mecanismos para transmissão de uma aula mais dinâmica, lúdica e prazerosa, por que não os aplicam? Nossos educadores são inertes a esses novos mecanismos de ensino ou simplesmente há total negligência no tocante à eficiência no processo de ensino-aprendizagem dos alunos com necessidades?

Segundo Schön (1992), uma crise que ocorre na Educação é a crise de conflito entre o saber e a reflexão na ação dos professores e alunos, onde se deve analisar que tipos de formação serão mais viáveis para equiparar professores com as capacidades necessárias ao desempenho de seu trabalho, e nisto se refere a falta de preparação do professor com crianças surdas, estes profissionais necessitam de um conhecimento em LIBRAS, e na maioria dos casos não são preparados para esse tipo de ação. Nesse sentido, a teoria desenvolvida por Donald Schön quando aborda a reflexão na ação e sobre a ação pode ser implementada para o ensino dos surdos, pois contribui para uma maior compreensão das perspectivas para a atuação dos professores, visto que neste processo o professor observa o aluno, detectando qual seu grau de compreensão e sua dificuldade, possibilitando assim, o experimento de rever sua ação durante o processo de ensino.

Assim, a proposta de Schön (1992) para a Formação de Professores parte do pressuposto de um profissional reflexivo pautado na premissa de aprender fazendo. Nesse sentido, o "professor reflexivo" diz respeito ao profissional da educação que observa, analisa e reflete sobre sua prática pedagógica, tendo em vista o aperfeiçoamento de sua atividade docente. Isso pressupõe a autoformação para uma prática mais consciente da sua responsabilidade pedagógica e do exercício político da profissão - elementos fundamentais para a formação da cidadania, mote sobre o qual se assenta a contribuição social da docência. (Shigunov Neto, Alexandre; Fortunato \& Ivan (org.) 2017, p.7).

O professor reflexivo, dentre outros aspectos, precisa problematizar a existência do aluno diferente, real, e assim contribuir na prática de professores mais flexíveis e reflexíveis as adversidades do contexto social educacional.

Segundo Piaget, o desenvolvimento cognitivo é um processo sequencial onde a interação tem importante papel no 
desenvolvimento das operações lógicas, pois influencia significativamente a visão de mundo do sujeito, permitindo-lhe evoluir de uma perspectiva subjetivista para a objetividade; este processo não é inato. Conforme o autor: "O desenvolvimento é um processo sequencial marcado por etapas; embora a sequência do desenvolvimento seja a mesma para todas as pessoas, a cronologia é variável de pessoa para pessoa".

Quando é realizada uma avaliação na evolução do homem na sociedade, percebe-se que a criança foi considerada um adulto em miniatura, ou quase um adulto. Seu valor era de acordo com sua classe social, pois eram educadas para o futuro das classes altas, enquanto as das classes baixas eram somente valorizadas quando a mesma podia ser útil ao trabalho, onde colaborava na geração da renda familiar. Portanto, é válido lembrar que a criança não é um adulto que ainda não cresceu (Ariès, 1981, p. 51). Ela necessita percorrer etapas de seu desenvolvimento para se tornar um adulto. A família é o primeiro apoio, que desenvolve etapas do cognitivo, emocional, físico e social e posteriormente, este grupo se amplia com os colegas de brincadeira e a escola.

Foram necessárias mudanças profundas na imagem da criança que pudesse associar uma visão para atividades espontâneas relacionadas a idade, em decorrência, surgiram leis que foram adequando a inclusão nas escolas regulares, e neste processo, até hoje muitos professores tem dificuldades pois não foram preparados para trabalhar com estas crianças.

A melhoria no processo de ensino e aprendizagem perpassa quando o professor se abdica de métodos tradicionais, observadas através do quadro branco ou quando se utiliza de recursos que não prendem a atenção dos alunos. Frente a essas observações, é fundamental, enfatizar a importância do uso de LIBRAS como um fator que propicie aos educandos uma aula mais harmoniosa, inovadora, lúdica, enfim, que confronte com os seus anseios, ensinando as crianças com deficiência auditiva e incentivando as crianças ditas normais a terem o conhecimento da LIBRAS, usadas pelos surdos e legalmente reconhecida como meio de comunicação e expressão no nosso País.

Estudos revelam que 90\% dos alunos com deficiência auditiva são filhos de pais ouvintes. (Santanna, 2007) Sendo assim, a vontade natural desses pais é procurar técnicas que reabilitem a audição e por consequência a oralização. Neste contexto, pode ocorrer um atraso no aprendizado e nas suas relações familiares, visto que essa interação é essencial na construção da personalidade e na formação social do sujeito (Schemberg, Guarinello \& Massi, 2012). Portanto, a escola tem um papel fundamental da garantia de um desenvolvimento intelectual com qualidade.

O desconhecimento e a falta de preparo tanto das famílias, como da sociedade, condenam o sujeito surdo a uma vida de exclusão, impedindo-o de se comunicar e expressar seus anseios e perspectivas.

De acordo com Paniagua (2004), a família de crianças com necessidades especiais passa por quatro processos até chegar à aceitação dessa condição. O do choque, quando os pais inconformados sentem um bloqueio, ocorrendo uma confusão de ideias e muitas vezes, negam a informação recebida; o da negação, fase complicada em que muitos recusam a condição de surdez da criança; o da reação, consiste em um turbilhão de emoções: ansiedade, sentimento de fracasso, culpa, irritabilidade e até mesmo depressão e por último, o de adaptação e orientação, onde os pais já conseguem controlar as suas ansiedades, buscam maiores informações acerca do que fazer e de como fazer para ajudar o seu filho.

Lima \& Vieira (2006) comenta que as crianças surdas de famílias ouvintes correm risco de séria privação de linguagem no início da vida e de uma incapacidade para apreender o que está acontecendo ao redor delas e o porquê (aprendizagem incidental), uma vez que seus pais não sabem comunicar-se com elas.

Para o ensino dos surdos é oportuno que seja utilizada como língua primordial a LIBRAS, uma vez que viabiliza o processo de comunicação, tanto no âmbito familiar, quanto no âmbito escolar em que eles são instigados a progredir e se desenvolver, visto que os surdos não desenvolvem a obtenção natural da língua oral. Damázio (2005, p.61) ressalta: “A Libras, língua brasileira de sinais, possibilita o desenvolvimento linguístico, social e intelectual daquele que a utiliza enquanto instrumento comunicativo, favorecendo seu acesso ao conhecimento cultural cientifico, bem como a integração no grupo social 
ao qual pertence."

A inclusão é um desafio que provoca mudanças na escola, redefinindo novas alternativas pedagógicas, que viabilize a todos os alunos, o que implica na renovação e fortalecimento de conceitos e em práticas escolares pertinentes com essa grande incitação.

Quando se fala em inclusão, é impossível não citar a importância da preparação do educador, visto que este trabalhará com uma diversidade de crianças e com suas particularidades. Segundo Cruz (2007), o profissional deve sempre estar estudando a respeito, a fim de se atualizar, melhorar e se capacitar cada vez mais.

É perceptível, a necessidade de mudanças no currículo e sugestionar métodos educacionais que sejam dipostos por toda a comunidade escolar, na busca de soluções para condições adequadas às necessidades dos educandos. Sendo assim, buscar o apoio da família na contribuição de estratégias para que a inclusão aconteça dentro e fora da escola.

A relação entre professor e aluno, deve ser mais próxima e para isso, o professor precisa de um conhecimento básico da língua de sinais. A partir daí, eles podem estabelecer uma parceria para pensar em práticas didáticas, estratégias metodológicas e materiais que favoreça o aprendizado (Lacerda, 2006).

A reflexão da inclusão, nota-se na solidariedade humana, no profissionalismo docente e no conhecimento das necessidades do outro. Para Ponte \& Oliveira (2002, p. 148): Conhecer os seus alunos como pessoas, os seus interesses, os seus gostos, a sua forma habitual de reagir, os seus valores, as suas referências culturais, e conhecer o modo como eles aprendem são condições decisivas para o êxito da atividade do professor.

A presença de intérprete, não é efetivamente inclusiva, visto que, o aluno surdo está inserido em um ambiente ouvinte, assim, o contato com o professor regente e com seus colegas será ínfimo, em razão que não saberão se comunicar com ele, ficando restrito somente ao intérprete, este, se responsabilizará totalmente pelo aluno.

Como comenta Guarinello (2006), para os professores “[...] o intérprete parece significar algo miraculoso e capaz de promover aos alunos surdos uma aprendizagem efetiva”, mas não basta a presença do interprete, é necessário que o professor em sala de aula, desenvolva procedimentos pedagógicos que possibilitem a aprendizagem e participação dos alunos surdos.

“A inclusão de surdos no ensino regular significa mais do que apenas criar vagas e proporcionar recursos materiais, requer uma escola e uma sociedade inclusivas, que assegurem igualdade de oportunidades a todos os alunos, contando com professores capacitados e compromissados com a educação de todos.” (Guarinello, 2006)

O aluno surdo entra na escola sem domínio de uma língua, ele terá que, ao mesmo tempo, constituir a língua e compreender os conceitos, gerando um atraso na aprendizagem. Focar na aquisição de materiais direcionados a estes alunos, proprocionará um ambiente mais agradável e em consequência uma interação maior entre o professor e aluno.

No que se refere ao ensino de matemática e ciências para surdos, há controvérsias, pois existem autores que não condizem em suas avaliações sobre o tema. Poucas são as pesquisas que tratam de métodos de ensino, aquisição e desenvolvimentos de conceitos e habilidades numéricas e cientifícas em alunos surdos.

Ao se observar o histórico da educação dos surdos, as estatísticas mostram que todas as atenções são voltadas a língua portuguesa, com isso, as demais disciplinas são esquecidas, sejam elas matemática, ciências, artes, entre outras.

Embora alguns pesquisadores acreditem que a linguagem matemática possibilita um maior desenvolvimento do surdo nessa disciplina, o que se vê hoje em relação à política educacional de inclusão e a educação matemática, são que os professores carecem de material bibliográfico que lhes permita adequar a metodologia utilizada em sala de aula para atender aos surdos.

O ensino da matemática requer um levantamento, em seus alunos surdos, sobre a aprendizagem de noções básicas, seja, de ordenação ou produção de sequências numéricas, que possibilitará o desenvolvimento de processos complexos como o da contagem. É provável, que algumas dificuldades de aprendizagem ocorram em função do ensino não adequado da ordenação e de outras habilidades pré-aritméticas, como se vê em Williams: 
Especificamente, crianças surdas mostram dificuldades significativas no desempenho de operações aritméticas básicas (Zboetekowa, 1993), as quais podem ser geradas a partir de relações numéricas e de quantidade inadequadas. Além do mais, adolescentes com impedimento auditivo tem demonstrado atrasos acadêmicos similares em respeito à matemática avançada. (Williams, 2000, p.5)

Destaca-se que para o ensino da matemática a utilização de meios visuais pode acarretar uma melhor aprendizagem, mas o conceito precisa ser compreendido e a necessidade de um suporte com recursos em LIBRAS para auxiliar nas referências visuais.

Segundo Nogueira; Machado (1996), os professores costumam considerar que a disciplina de matemática é a disciplina que menos apresenta dificuldade para as crianças, a exceção dos problemas, cujos entraves são atribuídos, não sem razão, às dificuldades óbvias de interpretação dos enunciados.

Observa-se também, que os educadores focam mais na prática de exercícios que em situações problemas, concernenetes as competências linguísticas, a invés de análises de estratégias.

Apesar da carência de material, compreende-se que a metodologia de matemática utilizada no ensino dos surdos, não modifica muito da que se usa com os alunos ouvintes, apesar de que a linguagem seja diferente. Nas séries iniciais, por exemplo, o uso de recursos ilustrativos como figuras e o letramento dos alunos para entendimento dos problemas, são iguais, devido à circunstância de que a memória visual e de eventos apresentados espacialmente de uma pessoa surda é substancialmente melhor do que a de uma ouvinte.

A matemática é geralmente vista como uma disciplina extremamente difícil, que lida com objetos e teorias abstratas e para alguns, se destaca o seu aspecto mecânico, associado ao cálculo, e é exatamente este aspecto mecânico que muitos acreditam que os surdos conseguem compreendê-la.

Dessa forma, facilita-se a compreensão da matemática, de suas características e propriedades, destacar suas contribuições, promover a interação social, cooperar, integrar e favorecer possibilidades de construção de conceitos matemáticos diversos, levará não só o aluno surdo, mas também o ouvinte, a crer em sua capacidade intelectual e a construir seu conhecimento lógico-matemático.

Segundo Gessinger (2001), os professores de matemática devem oferecer situações de ensino e aprendizagem em que os alunos possam construir conceitos matemáticos, podendo utilizar jogos, por exemplo, pois além do caráter lúdico, despertam atenção por serem prazerosos e auxiliam a criança a agir e se comunicar, e a partir do momento em que os próprios conhecimentos começarem a fazer parte do processo, se estabelecem relações entre os conceitos que se têm e os que irão surgir no decorrer da aprendizagem.

"A sociedade do conhecimento na qual vivemos, com transformações constantes no processo de produção e na construção de conhecimento, faz surgir novas demandas sobre o sistema educacional, exigindo que os professores desenvolvam novos saberes que viabilizem um processo de ensino/aprendizagem atualizado.” (Gomes, 2006, p. 72)

No caso da matemática, uma das maiores dificuldades que o docente encontra está na comunicação em sala de aula, em virtude da ampla utilização de simbologia, seja ela própria da matemática, seja própria da língua de sinais. Uma metodologia diferenciada é crucial para que os alunos construam meios para desenvolverem conhecimentos associados ao seu cotidiano, como também, na construção de conhecimentos matemáticos. Sendo assim, o diálogo com aquele a quem você se destina a ensinar é o principal caminho para a aprendizagem e o caminho para se estabelecer comunicação é a reflexão.

Um aspecto interessante e comum no ambiente escolar é o fato de que muitos alunos ouvintes quando alcançam sucesso em matemática, normalmente o alcançam também em outras disciplinas. O mesmo não acontece com frequência com os surdos. Não é raro encontrar alunos que obtêm sucesso em matemática e fracassam em outras disciplinas. Para Cukierkorn, a aprendizagem nessa disciplina se desenvolve com maior facilidade devido à linguagem matemática ser estruturalmente mais semelhante a LIBRAS do que ao português. 
A literatura aponta que é comum os alunos surdos terem mais sucesso em Matemática que em outras disciplinas, devido, possivelmente, à semelhança estrutural entre a LIBRAS e a Matemática, uma vez que, pelo fato da Matemática "ter em confronto com a linguagem oral (ou mesmo gestual), uma maior precisão na sua 'gramática', permite que esta área obtenha resultados mais satisfatórios" (Cukierkorn, 1996, p. 109).

A LIBRAS diferencia-se do português por ser um conjunto de movimentos e expressões que são captadas pela visão, mas também apresenta aspectos linguísticos, como: morfologia, sintaxe e normas. "Para os surdos, o português é aquilo que eles podem ver, uma vez que não têm o acesso às propriedades sonoras", explica: Linair Moura Barros Martins, coordenadora-geral de Articulação da Política de Inclusão dos Sistemas de Ensino do Ministério da Educação - MEC.

Faz-se necessário, também, que os órgãos competentes ajudem os professores e funcionários de escolas a se familiarizarem com estas estratégias para uma melhor aprendizagem nas disciplinas de matemática e ciências, hoje se atribui esta linguagem somente na área de Língua portuguesa.

A essência da atividade (prática) do professor é o ensino aprendizagem. Ou seja, é o conhecimento técnico pratico de como garantir que a aprendizagem se realize em consequência de atividade de ensinar. Envolve, portanto, o conhecimento do objetivo, o estabelecimento de finalidades e a intervenção no objeto para que a realidade seja transformada enquanto realidade social. Isto é, a aprendizagem precisa ser compreendida enquanto determinada por uma realidade histórico-social (Pimenta, 2001, p.61)

Ponte (2002) destaca que nem todo estudante de licenciatura "teve oportunidade, pela sua formação escolar e não escolar, de se desenvolver como pessoa e como cidadão o suficiente para poder vir a ser um bom professor" (p. 03), logo, a formação continuada desempenha um papel indispensável.

Os professores que ensinam Matemática precisam ter ao seu alcance material didático, ou instrucional, apropriado e de qualidade, com apelo tátil, visual e auditivo de modo a atender todos os alunos com deficiência, levando-os à construção de conceitos matemáticos, seja por meio de utilização de jogos didáticos, seja por meio de atividades lúdicas, para mobilizarem todos os alunos da sala de aula rumo a uma aprendizagem matemática mais significativa, pois “o professor desempenha um papel importante na criação de ambientes educacionais positivos e enriquecedores" para o aluno do ensino especial (Correia, 2003, p. $31)$.

“Os recursos utilizados para os ouvintes podem ser utilizados para os demais alunos, o que reque é uma abordagem e a uma metodologia, adequadas às especificidades de cada grupo de estudantes, em fim, a Matemática "é como um edifício em construção, sempre necessitando de modificações e adaptações" (Santaló, 1990, p. 19).

No que se refere especificamente aos alunos surdos, é possível chegar ao raciocínio lógico-matemático, com poucas adaptações em Libras, considerando que os mesmos captam as sensações do mundo diferente de nós. Cabe ao professor se sensibilizar, sentindo o mundo somente pela visão, assistindo uma apresentação sem utilizar a audição, para assim, propor metodologias que incentivem e incluam esses alunos, isto se ratifica no exposto da fala de Silva (2018):

Os problemas encontrados em meio à vida dos individuos surdos são problemas que não se acarretam exatamente por causa dessas pessoas, mas sim,por causa de uma situação contigente, devido à ausencia de uma aquisição natural espontanea em torno da linguagem e pelo receio que algumas pessoas possuem de se aproximar desses sujeitos.(SILVA,2018,p.22)

\section{Considerações Finais}

Atualmente os alunos surdos já estão sendo inseridos em escolas regulares. Todavia, falta muito para que esta inclusão de fato tenha efeito sobre questões históricas que envolvem principalmente a Língua de Sinais, como também a construção do conhecimento e aprendizagem pelos surdos. Eles, ainda, sofrem bullying e muito preconceito. É preciso entender que o surdo é uma pessoa que se comunica de forma diferente. 
É importante, falar sobre inclusão social e, mais ainda, é crucial ensinar ao cidadão a ter consciência de praticá-la. Estimular o uso da LIBRAS e propagar a sua difusão, promovendo o ensino em todas as escolas do país.

Incluir não é permitir que crianças com necessidades especiais frequentem escolas regulares, mas dar aos profissionais da educação, condições para trabalhar de forma coerente e pedagógica, com um método realmente inclusivo.

O professor na sua função de ensinar deve atender as especificidades de seus alunos, onde o aluno surdo é o foco de nosso estudo, sendo indispensável a reflexão sobre a prática de novas metodologias que proporcionem um processo de ensinoaprendizagem com estratégias para uma melhor aquisição nas disciplinas de matemática e ciências.

É interessante, portanto, destacar a necessidade do aprendizado da LIBRAS por pessoas ouvintes, que oconteça a capacitação de professores, a abertura de mais espaço para intérpretes e a efetivação da educação bilíngue, estas serão formas admiráveis de propiciar uma educação inclusiva.

Observamos que todo professor na sua especificidade deve atender seus alunos, que ele deve considerar as características linguísticas para que os alunos assimilem a ideia de mundo a sua volta, assim o profissional da educação necessita fazer uma reflexão sobre sua prática metodológica e assim proporcionar um melhor processo ensino-aprendizagem. Espera-se, verdadeiramente, que este artigo, além de levar pais, professores e profissionais da área de Matemática e Ciências a um maior aprofundamento do tema, contribua para o seu desenvolvimento pessoal presente e futuro como educadores, e principalmente, com o ser humano que muito aprende através da busca para melhor repassar, através da língua de sinais, os conteúdos para crianças surdas.

Ressalta-se que essa investigação faz parte da dissertação de mestrado que se encontra em desenvolvimento no Programa de Pós-Graduação em Ensino de Ciências e Matemática (PGECM), do Instituto Federal de Educação, Ciência e Tecnologia do Ceará (IFCE) - Campus Fortaleza, buscando-se fundamentar a relevância do objeto de estudo, no empenho de sanar lacunas práticas sobre a inclusão de crianças surdas, bem como da família, durante todo o processo de ensino e aprendizagem, para sua consolidação e, consequentemente, contribuição para uma efetiva inclusão.

Para isso, recomenda-se estratégias que fomentem, de forma efetiva e significativa, a formação inicial dos professores para atuar com LIBRAS no ambiente escolar, favorecendo a inclusão da cultura surda. Para isso, sugere-se mais produções acadêmicas em nível de artigos, dissertações e teses a fim de tornar rica a literatura relacionada a essa temática, bem como a devida inclusão da LIBRAS desde a formação docente, assim como no ambiente escolar da educação infantil aos níveis de educação superior.

"'Surdo' é aquele que não tem tempo de ouvir um desabafo de um amigo, ou o apelo de um irmão. Pois está sempre apressado para o trabalho e quer garantir seus tostões no fim do mês". (Mario Quintana).

\section{Referências:}

Alves, M. \& Ramos, A. (2018). Formação do Pedagogo para atuar na Educação Inclusiva: o Currículo da Faculdade de Educação da UFF. In Colóquio Internacional Educação, Cidadania exclusão. https://www.editorarealize.com.br/editora/anais/ceduce/2018/TRABALHO_EV111_MD4_SA10_ID432_04052018192041.pdf

Ariès, P. (1981). História Social da Criança e da Família. 2. ed. Rio de Janeiro: LTC.

BrasiL(1994). Declaração de Salamanca e Linhas de ação sobre necessidades educativas especiais. http://portal.mec.gov.br/seesp/arquivos/pdf/salamanca.pdf Brasil (2002), Lei Federal N. 10436 de 24 de abril de 2002: Oficializa a Língua Brasileira de Sinais em território nacional. Brasil (2005), Decreto N. 5626/2005: Regulamenta a Lei n. 10436/2002, que oficializa a Língua Brasileira de Sinais. Brasília.

Correia, L. M. (2003), Educação Especial e Inclusão: Quem disser que uma vive sem a outra não está no seu perfeito juízo. Porto: Porto Editora. 
Cruz, G. C. (2007), Formação continuada de professores de educação física ante a provocação da inclusão escolar. In: Manzini, E. J. Inclusão do aluno com deficiência na escola: os desafios continuam. Marília. p. 127-137.

Damázio, M. F (2005), Educação Escolar Inclusiva de Pessoas com Surdez na Escola Comum-Questões Polêmicas e Avanços Contemporâneos. Brasil.

Gessinger, R. M. (2001), Alunos com Necessidades Educacionais Especiais nas Classes Comuns:relatos de professores de Matemática. Dissertação (Mestrado em Educação) - Faculdade de Educação, PUC-RS, Porto Alegre.

Gomes, J. O. M. (2006), A formação do Professor de Matemática: um estudo sobre Implantação de novas metodologias nos cursos de licenciatura de Matemática da Paraíba. Dissertação (Mestrado) - Universidade Federal da Paraíba, João Pessoa.

Goldfeld, M (2002). A criança surda - linguagem e cognição numa perspectiva sociointeracionista. 2 ed. São Paulo: Plexus

Guarinello, A. C. (2006), et al. A inserção do aluno surdo no ensino regular: visão de um grupo de professores do Estado do Paraná. Revista Brasileira de Educação Especial.

Lacerda, C. B. F. de (2006), A inclusão escolar de alunos surdos: o que dizem alunos, professores e intérpretes sobre esta experiência. Caderno CEDES, Campinas, v. 26, n. 69.

Lima, P. A. \&Vieira, T. (2006), Surdos: a(s) linguagem (s) como sistemas de representação e organização mental. São Paulo: Avercamp.

Nogueira, C. M. I. \&Machado, E. L. (1996), O Ensino de Matemática para DeficientesAuditivos: uma visão psicopedagógica. p.160. Relatório final de Projetode pesquisa - Universidade Estadual de Maringá - PR.

Nóvoa, A. (2009), Professores: Imagens do futuro presente. Lisboa: Educa.

Pereira, C. L \& Santos, M. (2009), Educação Inclusiva; uma breve reflexão sobreos avanços no Brasil, após a Declaração de Salamanca. Revista da Católica. Uberlandia, v.1,n.2p.265-274.

Pimenta, S. G. (2001) O estágio na formação dos professores: unidade teoria e prática.4 ed. São Paulo: Cortez.

Ponte, J. P. (2002), A vertente profissional da formação inicial de professores de Matemática. Educação Matemática em Revista, São Paulo, n. 11A, pp. 03-08.

Ponte, J. P. \& Oliveira, H. (2002). Remar contra a maré: a construção do conhecimento e da identidade profissional na formação inicial. Revista de Educação, v. 11, $\mathrm{n}^{\mathrm{o}}$ 2. Lisboa: Universidade de Lisboa.

Ramalho, I. B. \& Núñez, B. L. (2011) Diagnóstico das necessidades formativas de professores do ensino médio no contexto das reformas curriculares. Revista Educação em Questão, Natal- UFRN.

Santaló, L. A. (1990). Matemática para Não-Matemáticos. In: Parra, Cecilia; Saiz, Irma (Orgs) (1996), Didática da Matemática: Reflexões Psicopedagógicas. Porto Alegre: Artmed.

Santana, A. P. Surdez e linguagem: aspectos e implicações neurolinguísticas. São Paulo: Plexus, 2007.

Schemberg, S., Guarinello, A. C., \& Massi, G. (2012), O ponto de vista de pais e professores a respeito das interações linguísticas de crianças surdas. Revista Brasileira de Educação Especial, 18(1), 17-32.

Schön. D. formar professores como profissionais reflexivos. In: Nóvoa, A. (Coord) (1992). Os professores e a sua formação. Lisboa: Dom Quixote, 1992, p.7991

Severino,A. J. Metodologia do Trabalho Cientifico.São Paulo.Cortez Editora.

Shigunov N, A. \& Fortunato, I. (org.) (2017), 20 anos sem Donald S chön: o que aconteceu com o professor reflexivo? São Paulo:Edições Hipótese, 2017. p. 7.

Silva,T. B. A, O surdo na escola. $1^{\text {a }}$ Ed. São Paulo: Editora Letras e Versos, 2018

Strobel, K. L. (2008), As Imagens do Outro sobre a Cultura Surda. Florianópolis: UFSC.

Paniagua, G. (2004). As famílias de crianças com necessidades educativas especiais. In: César C, Álvaro M. \& Jesus, P. (2004), Desenvolvimento psicológico e educação. Trad. Fatima Muranda. 2 ed. Porto Alegre: Artmed.

Williams, K. D. (2000), Teaching Pre-math SkillsVia Stimulus Equivalente Procedures. Master Thesis-Southern Illinois University at Carbondale. Unpuplished Manuscript. 